\title{
To Study the Orientation of Anganwadi Workers on Integrated Management of Neonatal and Childhood IIIness in Malnutrition
}

\author{
Tarun Naik ${ }^{1}$, Bhagat Baghel ${ }^{2}$ \\ ${ }^{1}$ Assistant professor in LTBRKM, Pediatric Department, Gov Medical College Jagdalpur, , ${ }^{2}$ Associate professor in LTBRKM, Pediatric Department, Gov Medical College \\ Jagdalpur.
}

\section{Abstract}

Background: Malnutrition is one of the serious health problems in children. Malnourished children are more prone to frequent illness. This adversely affects their nutritional status, faltering growth and diminished learning ability. India adapted the integrated management of childhood illness strategy aiming to reduce its newborn and infant mortality burden and the main objective of the study was the orientation of anganwadi workers on IMNCI in malnutrition. Subjects and Methods: The study was observational and conducted jagdalpur Chhattisgarh. Only those who fully satisfied both the inclusion and exclusion criteria were included in the study. Permission from institutional ethics committee was obtained. Selection criteria in the present study were all children in the Anganwadi in a defined area. Result: PEM cases are more compared to controls, Malnutrition is seen in below 5 years of age group in children and more in cases group than the control group. In cases group it was 360 and control group it was 240.In $0-2$ months of age malnutrition is more in cases than controls. Conclusion: Anganwadi workers were trained based on IMNCI and asked to educate mothers regarding health, nutrition and care seeking during illness of the children.

Keywords: Malnutrition, Anganwadi workers, childhood illness.

Corresponding Author: Dr. Bhagatbaghel, MD, Paediatrics, Shadan Institute of Medical Sciences, Hyderabad, Telangana, India.

Received: January 2020

Accepted: January 2020

\section{Introduction}

Malnutrition is one of the serious health problems in children. Malnourished children have lowered resistance to infection; therefore they are more likely to die from childhood ailments such as diarrheal diseases and respiratory infections. Malnourished children are more prone to frequent illness. This adversely affects their nutritional status, faltering growth and diminished learning ability. ${ }^{[1]}$

India adapted the integrated management of childhood illness strategy aiming to reduce its newborn and infant mortality burden and renamed the revised strategy integrated management of neonatal and childhood illness. It incorporates home visits for early new born care. ${ }^{[2]}$

During deliveries blade was used to cut the cord, applied a substance to the cord immediately after cutting. Newborns are bathed within 24 hours. Babies are thought to be polluted and bathed soon after birth to clean and purify the newborn. ${ }^{[3]}$

Study of children having malnutrition, normally nourished 237, mild grade malnutrition 209, moderate grade malnutrition 129 and severe grade malnutrition 25. ${ }^{[4]}$

In this study out of 4792 mothers interviewed 2729 of woman washed their hands before the birth of the baby.
Once the umbilicalcord was cut the umbilical stump oil was applied in $18 \%$ cases, in $2 \%$ cases turmeric was applied. Colostrum was discarded before the first feed in 2416 cases. ${ }^{[5]}$

\section{Subjects and Methods}

The study was observational and conductedin jagdalpurChhattisgarh. In about 400 children. Only those who fully satisfied both the inclusion and exclusion criteria were included in the study. Permission from institutional ethics committee was obtained. Selection criteria in the present study were all children in the Anganwadi in a defined area under 5year's age. The study was conducted for a period of 2 years i.e. 2009 - 2011.For the study, each anganwadi center covers a population of 1000 having 10 $15 \%$ of under five years of children in oneCentre. 30 Anganwadi workers were selected out of which only 25 participated in the study. They were given training based on IMNCI for about three hours for three days. After about six months of training Anganwadi workers collected data by MCQ questionnaire based on IMNCI and in local language. These questions were regarding about common childhood illnesses. 


\section{Inclusion Criteria}

- All children in the Anganwadi in a defined area under 5 years of age

\section{Exclusion Criteria}

- Children above 5 years are not considered.

Results

Table 1: Malnutrition-Under mentioned table shows the timings of starting of weaning in months

\begin{tabular}{|l|l|l|}
\hline S.No & Case & Control \\
\hline 1 & 6 & 7 \\
\hline
\end{tabular}

Table 2: Total number of malnourished children in cases are $260(65 \%)$ and in control group are $280(70 \%)$ out of the total 400 children studied

\begin{tabular}{|l|l|l|}
\hline S.No & Case & Control \\
\hline 1 & 260 & 280 \\
\hline
\end{tabular}

Table 3: Malnutrition: The table shows the number of children who are below 5 years of age in both case and control group. PEM (Protein Energy Malnutrition)

\begin{tabular}{|l|l|l|}
\hline Categories & Case & Control \\
\hline PEM 1 & 169 & 144 \\
\hline PEM 2 & 52 & 52 \\
\hline PEM 3 & 26 & 48 \\
\hline PEM 4 & 13 & 36 \\
\hline Normal & 140 & 120 \\
\hline
\end{tabular}

Table 4: After how much time breast feeding started in the deliveries in case and control group

\begin{tabular}{|l|l|l|}
\hline Categories & Case & Control \\
\hline Immediately & 60 & 30 \\
\hline After 2 hours & 80 & 90 \\
\hline One day & 50 & 60 \\
\hline After 2 day & 10 & 20 \\
\hline
\end{tabular}

\section{Discussion}

According to Jeeson C, Richard et al a total of 271 infants were studied out of which 139 boys and 132 girls. 64\% belongs to middle class and $33 \%$ belongs to poor families. Four mothers completely weaned their infants by 6 weeks and 27 by 22 weeks. Supplements were offered to $18 \%$ of infants by 6 weeks and to $64 \%$ by 22 weeks. $58 \%$ of bottle feed infants were initially offered diluted cow's milk $28 \%$ were given diluted commercial milk substitute. By 22 weeks, $70 \%$ of bottle feed infants received either full cow's milk or formula feed. Solids were started for a few babies by 10 weeks of age. Up to 18 weeks; most infants were weaned using commercial weaning food mainly by rice and rice products. ${ }^{[6]}$

S B Bavdekar, SY Joshi, S Hathi et al reported about 153 mothers who were having children below 2 years were interviewed in two slum areas of Bombay. 27 infants below the age of 120 days, only 10(37\%) could be classified as completely breast feed. Three breasts feed infants also received cow's milk, buffalo's milk or formula milk as additional source of food. In the age group of $12-15$ months, 19 out of 26 infants received breast milk and in the age group of $20-23$ months, 22 out of 36 received breast milk $^{[7]}$

Anuradha goyal et al reported 294 mothers were asked about the breast feeding and infant feeding practices followed by them. 42(14.3\%) mothers out of 294 had given colostrum to their babies while $252(85.7 \%)$ had deprived their babies of this valuable food. The main reason for this is the literacy status of the mothers which was poor $98.3 \%$ mothers was illiterate. The reason for discarding colostrum is that the mothers of the babies thought it to be immature dirty milk and therefore harmful to their infants. ${ }^{[8]}$

$\mathrm{R}$ Singh et al reported most of the deliveries were attended by the physicians and 21.1 by trained medical personal as nurse, midwife, trained Dai etc. which shows that they utilized the modern facilities because $63 \%$ of the mother surveyed were literate and only $37 \%$ of mothers were illiterate. ${ }^{[9]}$

Shally Awasthi et al reported only $20 \%$ of infants were exclusively breastfeed for $5-6$ months and $41 \%$ exclusively breastfeed for less than 2 months. Children who were given only breastfeed for two months weighed $4.5 \mathrm{~kg}$ as compared to $6 \mathrm{~kg}$ for children exclusively breastfeed for 6 months. ${ }^{[10]}$

\section{Conclusion}

Educational intervention to improve care seeking for childhood illness in different settings should be developed. Anganwadi workers were trained based on IMNCI and asked to educate mothers regarding health, nutrition and care seeking during illness of the children. The efforts of imparting any amount of knowledge to them would prove useful. Health education should be such a way that each and every mother should have knowledge regarding newborn care, diarrhea, pneumonia, malnutrition and other infectious diseases.

\section{References}

1. Nguyen Ngoc Hein et al, Nutritional status and characteristics related to malnutrition in children less than 5 years of age in Vietnam. J Prev Med Public Health 2008; 41 (4):232- 240.

2. Nita Bandari, sarmila Majumdar et al, Effect of implementation of integrated management of neonatal and childhood illness programme on neonatal and infant mortality.BMJ journal.2012; 344:e1634

3. MD Ashraful Alam, Peter J, Winch et al (2010); new born umbilical cord and skin care in sylhet district. Bangladesh: Implications for promotion of umbilical cord cleansing with topical chlorhexidine. J Perinatal. 2008 December, 28(suppl 2): S61 -S68.

4. Mridula D, CP Mishra, p Srivastava et al ( 2004); Nutritional status of at risk under 5 of urban slums of Varanasi. Indian journal of preventive and social medicine, volume 35; No $1 \& 2,2004$.

5. David Osrin, Kirti M,Anthony M De L Costello et al(2002); Cross sectional, community based study of care of newborn infants in Nepal. BMJ Volume 325, 9 November 2002. 


\section{Naik \& Baghel; Integrated Management of Neanatal and Childhaad Illness}

6. Jesson C Unni, J Richard et al (1986); infant feeding in urban south Indian families. Indian pediatrics, volume 23- January 1986.

7. S B Bavdekar, sy joshi et al (1993); infants feeding practices in Bombay slums. Indian pediatrics, volume 31, September 1994.3

8. Anuradha Goyal, Preeti Jain, Harsha Saraf, Neetu Shekhawat et al (2004);Colostrum and prelacteal feeding practices followed by families of pavement and roadside squatter settlements in Jaipur city, Indian J, Prev. Soc. Med Vol 35 No 1 \& 2. Jan - June 2004.

9. R Singh, O A Kumar, R S Rana et al (1990); Breast feeding and weaning practices among urban Muslims of Lucknow. Indian pediatrics volume 29, 1992.

10. Shally Awasthi, Siddharth Agarwal et al (2003); Determinants of childhood mortality and morbidity in urban slums in India. Indian pediatrics, volume 40 - December 17, 2003.

Copyright: () the author(s), 2020. It is an open-access article distributed under the terms of the Creative Commons Attribution License (CC BY 4.0), which permits authors to retain ownership of the copyright for their content, and allow anyone to download, reuse, reprint, modify, distribute and/or copy the content as long as the original authors and source are cited.

How to cite this article: Naik T, Baghel B. To Study the Orientation of Anganwadi Workers on Integrated Management of Neonatal and Childhood Illness in Malnutrition. Asian J.Clin.Pediatr. Neonatol.2020;8(1):24-26.

DOI: dx.doi.org/10.47009/ajcpn.2020.8.1.6

Source of Support: Nil, Conflict of Interest: None declared. 